\title{
Novel hydrogenases from deep-sea hydrothermal vent metagenomes identified by a recently developed activity-based screen
}

\author{
Nicole Adam ${ }^{1} \cdot$ Mirjam Perner ${ }^{1}$
}

Received: 10 May 2017 / Revised: 10 November 2017 / Accepted: 5 December 2017 / Published online: 17 January 2018

(c) International Society for Microbial Ecology 2018

\begin{abstract}
Hydrogen is one of the most common elements on Earth. The enzymes converting molecular hydrogen into protons and electrons are the hydrogenases. Hydrogenases are ubiquitously distributed in all three domains of life where they play a central role in cell metabolism. So far, the recovery of hydrogenases has been restricted to culture-dependent and sequence-based approaches. We have recently developed the only activity-based screen for seeking $\mathrm{H}_{2}$-uptake enzymes from metagenomes without having to rely on enrichment and isolation of hydrogen-oxidizing microorganisms or prior metagenomic sequencing. When screening 14,400 fosmid clones from three hydrothermal vent metagenomes using this solely activity-based approach, four clones with $\mathrm{H}_{2}$-uptake activity were identified with specific activities of up to $258 \pm 19 \mathrm{nmol} \mathrm{H}_{2} / \mathrm{min} / \mathrm{mg}$ protein of partially purified membrane fractions. The respective metagenomic fragments exhibited mostly very low or no similarities to sequences in the public databases. A search with hidden Markov models for different hydrogenase groups showed no hits for three of the four metagenomic inserts, indicating that they do not encode for classical hydrogenases. Our activity-based screen serves as a powerful tool for the discovery of (novel) hydrogenases which would not have been identified by the currently available techniques. This screen can be ideally combined with culture- and sequence-based approaches to investigate the tremendous hydrogen-converting potential in the environment.
\end{abstract}

\section{Introduction}

Hydrogen is one of the most abundant, ubiquitously distributed compounds on Earth [1]. In Bacteria, Archaea, and lower eukaryotes, hydrogen plays a central role for metabolic processes [2-5]: for example, hydrogen oxidation catalyzed by membrane-bound hydrogen-converting enzymes essentially drives the synthesis of ATP which can provide energy for autotrophic carbon fixation. In contrast, enzymatic hydrogen production can recycle reducing equivalents in microbial fermentation. The enzymes catalyzing the interconversion of molecular hydrogen to protons and electrons $\left(\mathrm{H}_{2} \leftrightarrow 2 \mathrm{H}^{+}+2 \mathrm{e}^{-}\right)$are the hydrogenases. Currently three

Electronic supplementary material The online version of this article (https://doi.org/10.1038/s41396-017-0040-6) contains supplementary material, which is available to authorized users.

Mirjam Perner

mperner@geomar.de

1 Molecular Biology of Microbial Consortia, University of Hamburg, Biocenter Klein Flottbek, Ohnhorststr. 18, 22609 Hamburg, Germany types of hydrogenases are known which are classified according to their catalytic center: (i) [NiFe]-hydrogenases, (ii) $[\mathrm{FeFe}]-h y d r o g e n a s e s$, and (iii) [Fe]-hydrogenases [5]. [NiFe]-hydrogenases are usually associated with hydrogen sensing and consumption, [FeFe]-hydrogenases are the socalled hydrogen-evolving hydrogenases, and [Fe]-hydrogenases are involved in methanogenesis $[5,6]$.

Hydrogenases have often been identified by culturedependent methods [7, 8]. However, since the majority of microorganisms are currently not culturable (>99\%) [9], the use of culture-independent approaches has increased significantly. Computational screening of metagenomic sequence data sets or PCR-based DNA screens have identified conserved motifs of hydrogenase genes [10-12]. Yet, no information on whether the genes encode functional hydrogenases can be gained with this technique. Also, sequence-based analyses cannot aid in discovering new hydrogenases, since this method only identifies hydrogenases if similar ones are already available in the public databases. To date, function-based screening of metagenomes represents the only means for the discovery of truly novel enzymes [13] from the tremendous potential hidden among the microbial unculturables. 
Heterologous expression of hydrogenases in a surrogate host often proves to be difficult due to the highly specific maturation and assembly apparatus of hydrogenase enzymes, requiring several additional proteins [14-16]. Despite this, the expression of recombinant hydrogenases has been performed successfully in the past [17], also with metagenomic DNA sequences (but where hydrogenases were identified by sequence-based analyses first) [18].

In hydrothermal vent systems hydrogen can be highly enriched in the emitted fluids because of serpentinization processes (rock water interactions) or magma degassing [19, 20]. Here microbial hydrogen oxidation can be vital for providing energy to fuel autotrophic carbon fixation [21, 22]. Since these types of habitats are commonly hallmarked by steep thermal $\left(4^{\circ} \mathrm{C}\right.$ to several $\left.100 \mathrm{~s}{ }^{\circ} \mathrm{C}\right)$ and chemical (oxic to anoxic) gradients [12, 23], a broad repertoire of hydrogen-oxidizing microorganisms producing enzymes with distinct biochemical properties can be expected. Generally, a high diversity among membrane-bound $\mathrm{H}_{2}$-uptake [NiFe]-hydrogenases can be observed in hydrothermal fluids [12], but it has remained unresolved whether these hydrogenases are indeed functional.

We recently developed the first solely activity-based screen to seek $\mathrm{H}_{2}$-uptake enzymes from fosmid metagenomic libraries [24]. This activity-based screen complements an [NiFe]hydrogenase deletion mutant of Shewanella oneidensis MR-1 (S. oneidensis $\Delta$ hyaB) with an $\mathrm{H}_{2}$-uptake active metagenomic fosmid clone - restoring the original phenotype. It makes use of $S$. oneidensis MR-1's ability to couple hydrogen oxidation (catalyzed by the $[\mathrm{NiFe}]-$ hydrogenase $\mathrm{HyaA} / \mathrm{HyaB}$ ) with the reduction of $\mathrm{Fe}(\mathrm{III})$ citrate to $\mathrm{Fe}(\mathrm{II})$ citrate [25]. The $\mathrm{Fe}$ (III) reduction reaction results in a color change (from yellow to colorless) of FW medium, which is used for the chemolithotrophic growth of $\mathrm{S}$. oneidensis. If the [NiFe]-hydrogenase is deleted, as in the $S$. oneidensis mutant $\triangle h y a B$, no hydrogen can be converted, no electrons can be transferred to $\mathrm{Fe}$ (III), and thus no color change in the medium is visible (for details see ref. [24]). $\mathrm{H}_{2}$-uptake active metagenomic fosmid clones should restore the wild-type phenotype so that a color change can be observed again in the medium.

In the following we illustrate the feasibility of this activity-based screen to produce a functional hydrogenase from selected phylogenetically diverse isolates. We also present data on new $\mathrm{H}_{2}$-uptake active enzymes discovered from metagenomic fosmid libraries constructed with material from three deep-sea hydrothermal vent habitats with differing environmental parameters.

\section{Materials and methods}

An overview of the steps and procedures used in this work are given in the Supplementary Figure S1: (i) testing the screen's ability to successfully recover $\mathrm{H}_{2}$-uptake active enzymes from phylogenetically diverse hydrogen-oxidizing bacterial isolates and (ii) applying the screen to metagenomic fosmid libraries for seeking recombinant $\mathrm{H}_{2}$-uptake active enzymes.

\section{Cultivation of tested strains and DNA extraction}

Bacterial strains and plasmids used in this study are listed in Supplementary Table S1. S. oneidensis was cultivated at $28^{\circ} \mathrm{C}$ and Escherichia coli at $37^{\circ} \mathrm{C}$ in liquid lysogeny broth (LB) medium or on LB agar plates, solidified with $1.4 \%$ (w/v) agar. If required, the medium was supplemented with ampicillin $(100 \mu \mathrm{g} / \mathrm{l})$, gentamycin $(10 \mu \mathrm{g} / \mathrm{l})$, kanamycin $(30$ $\mu \mathrm{g} / \mathrm{l})$, and/or chloramphenicol $(12.5 \mu \mathrm{g} / \mathrm{l})$. S. oneidensis was also cultivated in serum bottles with rubber stoppers anaerobically with a modified mineral medium (FW) [26] containing $\mathrm{NaHCO}_{3}(2.5 \mathrm{~g} / \mathrm{l}), \mathrm{KCl}(0.1 \mathrm{~g} / \mathrm{l}), \mathrm{NH}_{4} \mathrm{Cl}(1.5 \mathrm{~g} / \mathrm{l})$, $\mathrm{NaH}_{2} \mathrm{PO}_{4} \cdot \mathrm{H}_{2} \mathrm{O}(0.6 \mathrm{~g} / \mathrm{l}), \mathrm{CaCl}_{2} \cdot 2 \mathrm{H}_{2} \mathrm{O}(0.1 \mathrm{~g} / \mathrm{l}), \mathrm{Fe}(\mathrm{III})$ citrate (3.0 g/l), L-arginine $(0.02 \mathrm{~g} / \mathrm{l})$, L-glutamine $(0.02 \mathrm{~g} / \mathrm{l})$, L-serine $(0.02 \mathrm{~g} / \mathrm{l}), 10 \mathrm{ml} / \mathrm{l}$ vitamin solution [27], and $10 \mathrm{ml} / \mathrm{l}$ trace element solution [28]. Oxygen was removed from the FW medium by flushing the hot medium with $\mathrm{N}_{2}$ (5.0, Westfalen AG, Münster, Germany) for $1 \mathrm{~h}$. Serum bottles with a volume of $120 \mathrm{ml}$ were sparged with $\mathrm{N}_{2}$, filled with $50 \mathrm{ml} \mathrm{FW}$ medium, sealed with butyl-rubber stoppers, and the headspace was replaced with $\mathrm{H}_{2} / \mathrm{CO}_{2}$ gas $(80 \% / 20 \%$ (v/v), Westfalen AG). Desulfovibrio vulgaris Hildenborough was cultivated using Medium 63 from the DSMZ (Deutsche Sammlung von Mikroorganismen und Zellkulturen, Braunschweig, Germany) in serum bottles sealed with butyl-rubber stoppers at $37^{\circ} \mathrm{C}$. Thiobacillus denitrificans $\mathrm{AB} 7$ and Sulfurimonas denitrificans DSM1251 were grown anaerobically in liquid Medium 113 (DSMZ), distributed in serum bottles sealed with butyl-rubber stoppers at $30^{\circ} \mathrm{C}$. Photobacterium leiognathi L1 was cultivated in liquid Medium 514 (DSMZ) aerobically at $28^{\circ} \mathrm{C}$. Cultures of Rhodobacter capsulatus SB1003 were grown in RCV medium [29] at $25^{\circ} \mathrm{C}$. Serum bottles with a volume of $200 \mathrm{ml}$ were filled with $200 \mathrm{ml}$ of RCV medium, sealed with butyl-rubber stoppers, and the headspace was replaced by oxygen-free $\mathrm{N}_{2}$ gas (5.0, Westfalen AG). Phototrophic growth was promoted by cultivation in the light. Wolinella succinogenes DSM1740 was cultivated in basal medium with fumarate [30] at $37^{\circ} \mathrm{C}$. Aliquots of $100 \mathrm{ml}$ of the oxygen-free medium were filled into serum bottles with a volume of $200 \mathrm{ml}$. The bottles were sealed with butylrubber stoppers and the headspace was replaced by $\mathrm{H}_{2} / \mathrm{CO}_{2}$ gas $(80 \% / 20 \%(\mathrm{v} / \mathrm{v})$. Genomic DNA of $E$. coli $\mathrm{K}-12$, S. oneidensis MR-1, P. leiognathi L1, W. succinogenes DSM1740, $S$. denitrificans DSM1251, $R$. capsulatus SB1003, D. vulgaris Hildenborough, and T. denitrificans $\mathrm{AB} 7$ was isolated from culture volumes ranging from 10 to 
$200 \mathrm{ml}$ using the UltraClean Microbial DNA Isolation Kit (MO BIO Laboratories, Carlsbad, CA, USA). Genomic DNA of Aquifex aeolicus VF5 was obtained from Dr. H. Huber (University of Regensburg).

\section{Cloning of [NiFe]-hydrogenase genes}

[NiFe]-hydrogenase genes (large and small subunit) of $R$. capsulatus, T. denitrificans, D. vulgaris, E. coli, Thiomicrospira sp. SP-41, P. leiognathi, W. succinogenes, and A. aeolicus were amplified with Phusion Flash High-Fidelity PCR-Master Mix (Thermo Fisher Scientific, Waltham, MA, USA)) using the Primers and PCR conditions listed in Supplementary Table S2. Thiomicrospira's hydrogenase genes were amplified from clone $S$. oneidensis $\triangle$ hyaB:: pRS44_SP41_01H02, which contains the whole hydrogenase gene cluster (Hansen and Perner, unpublished data) and was also used for complementation experiments. Since hynS and hynL of $T$. denitrificans $\mathrm{AB} 7$ are separated by open reading frames encoding hypothetical proteins, hynS and hynL genes were amplified individually, digested with ScaI and ligated together with T4 DNA Ligase (Thermo Fisher Scientific) according to the manufacturer's instructions - taking care that the respective genes are in frame. The large subunit of the $S$. denitrificans [NiFe]-hydrogenase was cut out of the vector construct pBBR1MCS-2:: Suden_1435 [31] via double digestion with SacI/SacII (Thermo Fisher Scientific). As a negative control a metagenomic insert (84G4II) of $13 \mathrm{kbp}$ without any hydrogenase genes but a RubisCO gene cluster [32] was used. All amplified (or restricted) [NiFe]-hydrogenase genes as well as the 84G4II insert were end-repaired, ligated into pRS44 (for details see "Construction of (meta)genomic fosmid libraries") and the fosmids transferred into E. coli EPI300 T1R cells via heat-shock transformation [33]. Inserts were checked by Colony PCR with the respective primers and/or sequencing (Eurofins Genomics, Ebersberg, Germany) of fosmid ends with $\mathrm{pCC} 1 / \mathrm{pEpIFOS}$ forward and reverse sequencing primers (Epicentre, Madison, WI, USA).

\section{Sampling of hydrothermal environments and isolation of metagenomic DNA}

Samples of hydrothermal vent systems were taken during the MAR-SUED V cruise in 2009 by means of the remotely operated vehicle (ROV) KIEL6000. At the sulfide-rich, basalt-hosted venting site Sisters Peak $\left(4^{\circ} 48^{\prime} \mathrm{S}, 12^{\circ} 22^{\prime} \mathrm{W}\right)$, a piece of the massive sulfide chimney (sample 274ROV1B) was recovered and microbial DNA was isolated and amplified as described [23]. At the ultramafic, hydrogen-rich vent field Nibelungen $\left(8^{\circ} 18^{\prime} \mathrm{S}, 13^{\circ} 30^{\prime} \mathrm{W}\right)$ fluid samples (314ROV7-9) were taken with the KIPS system [34] at the interface of hot hydrothermal fluids and ambient seawater.
The detailed sample handling can be found elsewhere [21]. At the Lilliput venting site $\left(9^{\circ} 33^{\prime} \mathrm{S}, 13^{\circ} 13^{\prime} \mathrm{W}\right)$, lowtemperature hydrothermal fluid samples were taken with the KIPS system (for details concerning sample handling and storage see refs. [21, 34, 35]). Microbial DNA from fluid samples was isolated from polycarbonate filters (on which the samples were concentrated) and all extracts were amplified via multiple displacement amplification [32, 36, 37].

\section{Construction of (meta)genomic fosmid libraries}

Fosmid libraries were created using genomic DNA from $E$. coli K-12, S. oneidensis MR-1, P. leiognathi L1, W. succinogenes DSM1740, S. denitrificans DSM1251, R. capsulatus SB1003, D. vulgaris Hildenborough, and $T$. denitrificans $\mathrm{AB} 7$ as well as metagenomic DNA from the three vent environments. Repeated attempts to construct a genomic library for A. aeolicus failed. For the construction of the fosmid libraries, the broad host-range fosmid vector pRS44 was used [38]. Prior to the construction of fosmid libraries vector DNA was isolated, linearized, dephosphorylated, and purified as previously described [24]. (Meta)genomic DNA of sufficient concentration and purity was end-repaired, ligated into pRS44, and subsequently transduced into E. coli EPI300-T1R cells using the Copy Control $^{\mathrm{TM}}$ Fosmid Library Production Kit with pCC1FOS (Epicentre, Madison, WI, USA) according to the manufacturer's instructions with the modification of using the broad host range fosmid vector pRS44 instead of pCC1FOS [24]. For the genomic libraries constructed in this study 1152 clones each were picked and stored in 96-well microtiter plates. Metagenomic libraries consisted of 4800 clones each. The quality of generated fosmid clones was checked randomly by (i) insert size estimation via restriction enzyme digests (EcoRI, HindIII, BamHI; Thermo Fisher Scientific) and (ii) sequencing of fosmid ends with $\mathrm{pCC} 1 / \mathrm{pEpIFOS}$ forward and reverse sequencing primers (Epicentre). Mean insert sizes of metagenomic libraries were between 17 and $22 \mathrm{kbp}$. Random blast search [39] from sequenced fosmid ends showed highest homologies to microorganisms typically abundant in hydrothermal vent habitats such as Thiomicrospira crunogena, Geobacillus sp., Hydrogenivirga sp., or Aciduliprofundum sp. The genomic fosmid libraries from the cultured organisms had mean insert sizes of 32-43 kbp and sequencing related the fosmid inserts to the respective initial microorganisms (cf. Supplementary Fig. S2).

\section{PCR-based identification of [NiFe]-hydrogenase genes in (meta)genomic fosmid libraries}

The genomic libraries were each screened for the presence of the respective hydrogenase genes via polymerase chain 
reaction (PCR). As a template for PCR reactions DNA crude extracts of the E. coli cells harboring genomic fosmids were used. Cell material of a densely grown copy of a microtiter plate was pooled and $2 \mathrm{ml}$ of the cell suspension was harvested $\left(14,000 \mathrm{~g}, 90 \mathrm{~s}, 4^{\circ} \mathrm{C}\right)$. The pellet was resuspended in $100 \mu \mathrm{l}$ of $\mathrm{TE}_{\mathrm{DNA}}$ buffer $(10 \mathrm{mM}$ Tris, $0.1 \mathrm{mM}$ $\mathrm{Na}_{2}$ EDTA, pH 8.0) and boiled at $95^{\circ} \mathrm{C}$ for $10 \mathrm{~min}$. Cell debris was collected by centrifugation $(5600 \mathrm{~g}, 10 \mathrm{~min}$, $4{ }^{\circ} \mathrm{C}$ ) and the supernatant was stored at $-20^{\circ} \mathrm{C}$ until used further in PCR.

For the fosmid clones from cultured organisms the same [NiFe]-hydrogenase primer pairs and PCR conditions were used as for the cloning of the respective genes (Supplementary Table S2). Metagenomic fosmid libraries were screened using primers targeting highly conserved regions of genes encoding for the large subunit of [NiFe]-hydrogenases (hynL): (i) hynL110F/hynL410R [40], (ii) hynLGr.I 322F (5'-GTD CAY TTY TAY CAT YTK CA-3')/hynLGr.I 1068R (5'-ATA CCA WSH GTG NGT HAC ATC TTC$3^{\prime}$ ), and (iii) hynLGr.II 322F (5'-GTK CAT TTY TAY CAR TTG CA-3')/hynLGr.II 1149R (5'-ACC RTC WAC ATA WCC DGT ATA-3'). PCR conditions were as follows: initial denaturation $95^{\circ} \mathrm{C}$ for $5 \mathrm{~min}$ followed by 32 cycles of denaturation for $45 \mathrm{~s}$ at $95^{\circ} \mathrm{C}, 45 \mathrm{~s}$ annealing at $45^{\circ} \mathrm{C}$ (hynL110F/410R) or $48^{\circ} \mathrm{C}$ (hynLGr.I and hynLGr.II), and $75 \mathrm{~s}$ elongation at $72{ }^{\circ} \mathrm{C}$. In order to locate hydrogenasecarrying fosmids among 96 clone pools, the described PCRs were repeated for pooled material from rows and from columns of positively tested microtiter plates. Hydrogenasecarrying fosmids were isolated and fosmid ends were sequenced as described above. Blast searches were used to confirm the presence of [NiFe]-hydrogenase and maturation genes. Fosmids harboring hydrogenase genes were transferred into $S$. oneidensis MR-1 $\Delta$ hyaB via triparental conjugation and the function-based hydrogenase screen was applied to test their heterologous expression.

\section{Function-based screen for $\mathrm{H}_{2}$-uptake active enzymes}

The function-based screen is based on the complementation of a [NiFe]-hydrogenase deletion mutant of $S$. oneidensis MR-1 with an $\mathrm{H}_{2}$-uptake active fosmid clone. The deletion mutant was constructed by site-directed mutagenesis of hyaB (large subunit of the structural [NiFe]-hydrogenase gene) with the insertion of a gentamycin resistance cassette using the pNPTS138R6KT suicide vector [41] and standard protocols [42]. (Meta)genomic fosmids, fosmids containing [NiFe]-hydrogenase genes, and the negative control were transferred into $S$. oneidensis $\triangle$ hyaB by triparental mating as described [24]. Putative $\mathrm{H}_{2}$-uptake active clones were detected by a color change (from yellow to colorless, related to Fe(III)reduction) of the FW medium used for the chemolithotrophic growth of $S$. oneidensis. For the evaluation of the screening method single putative positive clones ([NiFe]-hydrogenase and genomic fosmid clones) were tested among 23 negative clones, 47 negative clones, and 95 negative clones. The negative fosmid clones were the $S$. oneidensis $\triangle$ hyaB clone $84 \mathrm{G} 4 \mathrm{II}$. The pool of 48 clones provided the highest throughput combined with reliable screening results and was therefore chosen for the screening of metagenomic fosmid libraries. If a positive pool was identified due to color change of the medium this pool ( 48 clones) was divided into two new pools each consisting of 24 clones and inoculated in FW medium. If the pool of 24 clones exhibited a color change it was further broken down into pools of eight clones and subsequently single clones until the clone responsible for the color change was identified. For this clone $\mathrm{H}_{2}$-uptake activity and hydrogen consumption was measured and the metagenomic insert sequenced. Due to partial difficulties with the growth of frozen DMSO cultures with small sample volumes (loss of insert) after storage for 6 to 8 weeks, conjugation steps had to be repeated for the pools of eight clones and the single clones. The fosmids of putative positive single clones were isolated and fosmid ends were sequenced (Eurofins Genomics) with $\mathrm{pCC} 1 / \mathrm{pEpIFOS}$ forward and reverse sequencing primers (Epicentre). The sequences were compared to entries in the public NCBI databases using blastx [39].

\section{Preparation of crude cell extracts and partial purification of recombinant $\mathrm{H}_{2}$-uptake active enzymes}

S. oneidensis MR-1 wild type, S. oneidensis $\Delta$ hyaB, and $S$. oneidensis $\triangle$ hyaB complemented with (meta)genomic genes encoding $\mathrm{H}_{2}$-uptake active enzymes were cultivated anaerobically on a large scale. A total culture volume of 500-600 $\mathrm{ml}$ were grown in serum bottles containing $50 \mathrm{ml}$ FW each under an $\mathrm{H}_{2} / \mathrm{CO}_{2}$ atmosphere $(80 \% / 20 \%(\mathrm{v} / \mathrm{v}))$ at $28{ }^{\circ} \mathrm{C}$ for up to 4 weeks. The hydrogenase deletion mutant and the negative control (deletion mutant with a hydrogenase-free metagenomic insert) were grown in FW medium supplemented with pyruvate $(15 \mathrm{mM})$ and fumarate $(7.5 \mathrm{mM})$ as electron donor and acceptor, respectively. Cells were harvested by centrifugation $\left(6500 \mathrm{~g}, 4{ }^{\circ} \mathrm{C}, 1 \mathrm{~h} 30 \mathrm{~min}\right)$ and washed with $20 \mathrm{mM}$ sodium phosphate buffer ( $\mathrm{pH}$ 7.0) containing $1 \mathrm{mM}$ dithithreitol (DTT). The partial purification of the hydrogenases was performed as previously described [18] with the following modifications: Cell disruption was performed under anaerobic conditions in an anaerobic chamber through sonication (Sonicator UP50H with sonotrode MS2, Hielscher, Germany) at $70 \%$ amplitude and cycle $0.5(6 \times 30 \mathrm{~s})$. Cell debris was removed by centrifugation $(14,000 \mathrm{~g}, 3 \mathrm{~min})$ and the supernatant was 
ultra-centrifuged $\left(100,000 \mathrm{~g}, 4{ }^{\circ} \mathrm{C}, 1 \mathrm{~h}\right)$ to separate the membrane from the soluble fraction. The supernatant of the ultracentrifugation step was saved as the soluble fraction and the membrane fraction was resuspended in $300-700 \mu \mathrm{l}$ of $20 \mathrm{mM}$ sodium phosphate buffer ( $\mathrm{pH} 7.0$ ) containing $1 \mathrm{mM}$ DTT (depending on the pellet size). Both fractions were tested for $\mathrm{H}_{2}$-uptake activity and the protein concentrations were determined according to Bradford [43].

\section{$\mathrm{H}_{2}$-uptake enzyme activity assay}

The hydrogenase activity assay was performed spectrophotometrically using oxidized methylviologen as an artificial electron acceptor and hydrogen as an electron donor. This assay was performed under strictly anaerobic conditions as previously described [18, 44, 45] but with some modifications. Glass cuvettes were filled with anoxic reaction mixtures containing $20 \mathrm{mM}$ sodium phosphate buffer (pH 7.0), $1 \mathrm{mM}$ DTT, and $20 \mathrm{mM}$ oxidized methylviologen and sealed with rubber stoppers. The cuvettes were flushed with $\mathrm{N}_{2}$ for $5 \mathrm{~min}$ and then small amounts of $5 \mathrm{mM}$ sodium dithionite solution were added until the mixture turned blue (indicating strictly anoxic conditions). The prepared (membrane) protein fractions were added to the reaction mixtures and the enzymatic reaction under $\mathrm{N}_{2}$ atmosphere was observed spectrophotometrically at $602 \mathrm{~nm}$ (V-630 UV VIS Spectrophotometer with EHCS-760 Peltier Cell Holder, Jasco, Groß-Umstadt, Germany) as control. Hydrogen oxidation was started by flushing the cuvettes with $100 \% \mathrm{H}_{2}$ gas (5.0, Westfalen AG) for $20 \mathrm{~s}$ and also spectrophotometrically observed. The samples were incubated at $25{ }^{\circ} \mathrm{C}$ (or $55{ }^{\circ} \mathrm{C}$ respectively) during the whole measurement. The $\mathrm{H}_{2}$-uptake activity was calculated using an extinction coefficient of $5.401 \mathrm{M}^{-1} \mathrm{~cm}^{-1}$ for $25^{\circ} \mathrm{C}$ [31] and $9.41 \mathrm{M}^{-1} \mathrm{~cm}^{-1}$ for $55^{\circ} \mathrm{C}$ (Nicolas Rychlik, personal communication).

$\mathrm{H}_{2}$-uptake activities were calculated as mean values from three independent measurements and errors are given as the respective standard deviation.

\section{Hydrogen consumption measurements}

In vivo $\mathrm{H}_{2}$-consumption measurements were performed with the deletion mutant $S$. oneidensis $\triangle$ hyaB, S. oneidensis $\triangle$ hyaB complemented with the four metagenomic fosmids encoding $\mathrm{H}_{2}$-uptake active enzymes, the [NiFe]hydrogenase gene cluster of $S$. oneidensis (clone $\mathrm{P} 5 \mathrm{H} 2$ ) as well as the $13 \mathrm{kbp}$ hydrogenase-free metagenomic fragment (clone 84G4II). The respective cultures were grown in serum bottles containing $50 \mathrm{ml}$ of $\mathrm{FW}$ medium under an $\mathrm{H}_{2} / \mathrm{CO}_{2}$ atmosphere $\left(80 \% / 20 \%\right.$ (v/v) at $28{ }^{\circ} \mathrm{C}$. The hydrogen concentration in the headspace was determined by gas chromatography using a ShinCarbon ST100/120 column (Restek Corporation, Bellefonte, PA, USA) in a Trace GC ultra gas chromatograph (Thermo Fisher Scientific Inc.) with a Pulse Discharge Detector (Vici Valco Instruments, Houston, TX, USA) and helium 6.0 (Westfalen) as carrier gas. For the measurements $0.5 \mathrm{ml}$ taken from the headspace of the cultures was diluted in $1254 \mathrm{ml}$ of $\mathrm{N}_{2}$ gas 5.0 (Westfalen) and $2 \mathrm{ml}$ of the mixture were injected into the GC. Hydrogen was measured directly after inoculation and after color change of the medium to colorless (color change indicative of $\mathrm{H}_{2}$-uptake activity). For the two negative controls (S. oneidensis $\triangle$ hyaB and $S$. oneidensis $\Delta$ hyaB::pRS44_84G4II), which showed no color change, weekly measurements were performed until the end of the experiments. All clones were measured in triplicates.

\section{Sequencing and sequence analysis of the metagenomic fragments}

The metagenomic inserts of the hydrogen-converting fosmid clones were sequenced using the PacBio RS II technique (Pacific Biosciences of California Inc., Menlo Park, CA, USA) and assembled according to PacBio's recommendations at GATC Biotech AG (Konstanz, Germany) and Microsynth AG (Balgach, Switzerlnd). The fosmids were isolated from the respective $E$. coli clones using the Presto Plasmid Mini Kit (Geneaid, New Taipei City, Taiwan) according to the manufacturer's instructions. Two equimolar fosmid DNA pools (consisting of two fosmids each) were sequenced with PacBio RS II. Orf search was performed using prodigal with metagenomic settings [46] and the detected orfs compared to entries in the public NCBI databases using blastp [39]. Additionally, a hidden Markov-model search was performed. Protein sequences of [NiFe]-hydrogenases groups 1 to 4 , [FeFe]-hydrogenases groups $\mathrm{A}$ to $\mathrm{C}$, as well as [Fe]-hydrogenases (listed in refs. [5, 10]) were retrieved from the public databases and aligned using t-coffee [47]. Hidden Markov models were created for each hydrogenase type using HMMERs hmmbuild with default settings and the metagenomic orfs were compared to them using HMMERs hmmsearch with default settings that were subsequently altered to a reduced bit score of 1.0 for single domains [48].

\section{Data availability}

Sequences of the $\mathrm{H}_{2}$-uptake active metagenomic clones were deposited in the National Center for Biotechnology and can be found under Genbank accession numbers MG456603-MG456606. 


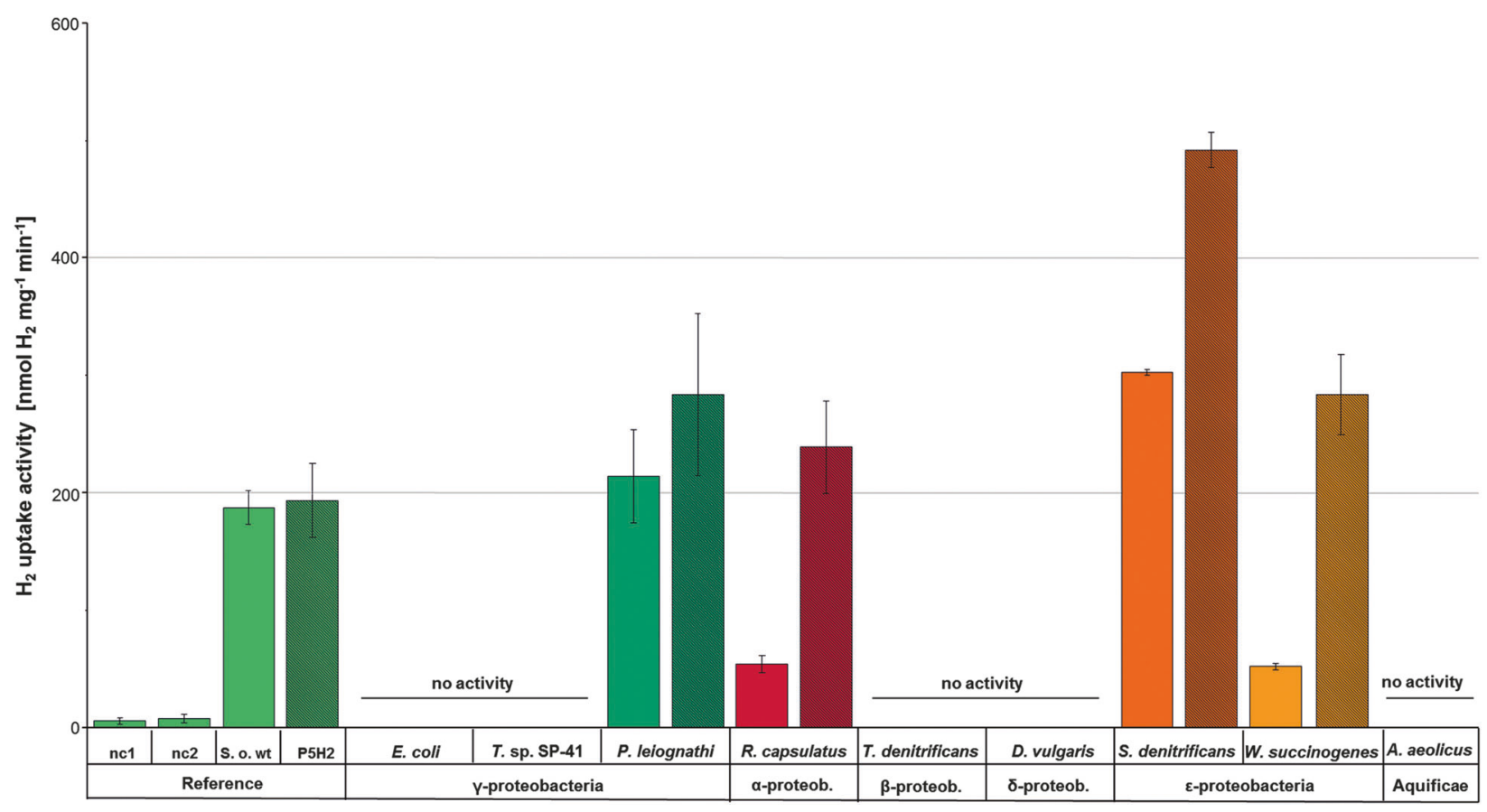

Fig. $1 \mathrm{H}_{2}$-uptake activities of $S$. oneidensis $\Delta$ hyaB complemented with different bacterial hydrogenase genes. All activities of partially purified membrane fractions of different $S$. oneidensis $\Delta$ hyaB clones as well as the $S$. oneidensis MR-1 wild type were measured at $25^{\circ} \mathrm{C}$. The negative controls $\mathrm{nc} 1$ and $\mathrm{nc} 2$ are the deletion mutant $S$. oneidensis $\triangle$ hyaB (nc1) and $S$. oneidensis $\triangle$ hyaB harboring a $13 \mathrm{kbp}$ hydrogenase-free metagenomic RubisCO gene cluster (84G4II) (nc2). The $S$. oneidensis wild type (S. o. wt) and S. oneidensis $\triangle$ hyaB with the $S$. oneidensis hydrogenase gene cluster $(\mathrm{P} 5 \mathrm{H} 2)$ are presented as

\section{Results and discussion}

\section{A novel activity-based screen for recovering $\mathrm{H}_{2}-$ uptake active enzymes from metagenomes}

Before seeking recombinant $\mathrm{H}_{2}$-uptake enzymes from metagenomic fosmid clones, we tested which [NiFe]hydrogenases from selected phylogenetically diverse isolates could be expressed to produce a $\mathrm{H}_{2}$-uptake active enzyme in our host-vector system (for hydrogenase phylogeny of tested isolates see Supplementary Fig. S3). Due to the highly specific maturation apparatus of hydrogenases, the heterologous expression of functional recombinant hydrogenases often fails [15]. For each tested isolate we expressed the hyaAB genes (in case of $S$. denitrificans only $h y a B$ was used) only or the entire hydrogenase gene cluster to elucidate whether (i) functional hydrogenases could be produced in our host and (ii) genes from the hydrogenase gene cluster were needed for expressing a functional structural hydrogenase. Our complementation experiments demonstrated that the heterologous expression of different proteobacterial $[\mathrm{NiFe}]$-hydrogenases in a hyaB deletion mutant of $S$. oneidensis is possible and can produce $\mathrm{H}_{2-}$ positive controls. The other activities shown are measured for $S$. oneidensis $\triangle$ hyaB complemented with the large ( $S$. denitrificans) or large and small subunit structural genes of the [NiFe]-hydrogenases of E. coli, Thiomicrospira sp., P. leiognathi, R. capsulatus, T. denitrificans, D. vulgaris, W. succinogenes, and A. aeolicus. The corresponding genomic fosmid library clones containing the hydrogenase gene clusters of the respective organisms (except for A. aeolicus) are shown as shaded bars

uptake active enzymes (Fig. 1; for more details see Supplementary Material).

\section{Seeking $\mathrm{H}_{2}$-uptake active enzymes from hydrothermal vent metagenomes}

The activity-based screen was applied to metagenomic fosmid libraries constructed with DNA from three different hydrothermal vent environments. These were the Sisters Peak chimney, hydrothermal fluids emanating from a crater at Nibelungen and low-temperature fluids from the Lilliput field along the southern Mid-Atlantic Ridge. Each library consisted of 4800 fosmid clones. Of the 14,400 screened clones, 4 clones exhibited $\mathrm{H}_{2}$-uptake activity, which equals a hit rate of 1:3600 clones. The hit rates of function-based screens targeting distinct enzyme activities can vary considerably, depending on the target enzyme distribution, heterologous gene expression, and the sensitivity of the screening method (influenced by host-vector systems and heterologous gene expression) [49]. However, hit rates are usually rather low (1:10,000 clones or $1: 2.7 \mathrm{Mbp}$ to $1: 3980 \mathrm{Mbp}$ of screened DNA) $[50,51]$. Taking into account that our fosmids have an 
average insert size of $20 \mathrm{kbp}$, we had a rather good hit rate of 1:72 Mbp for our $\mathrm{H}_{2}$-uptake screen.

\section{$\mathrm{H}_{2}$-uptake activity and hydrogen consumption}

From the four newly discovered $\mathrm{H}_{2}$-uptake active clones, two clones were from Sisters Peak, one from Nibelungen, and one from the Lilliput metagenomic libraries. The Sisters Peak chimney is hallmarked by a steep thermal $\left(400-4{ }^{\circ} \mathrm{C}\right)$ and chemical gradient along its cross section, fluids have $1.6 \mathrm{mM}$ hydrogen, and hydrogenases have been identified [23]. Hot fluids at Nibelungen $\left(120^{\circ} \mathrm{C}\right)$ emanate from a depression forming a crater structure and the sampled fluids had $22 \mu \mathrm{M}$ hydrogen related to ongoing serpentinization reactions [21]. The Lilliput fluids are low-temperature emissions from mussel patches where hydrogen concentrations are comparably low $(<1 \mu \mathrm{M})$ [35] (for an overview on some environmental characteristics see Supplementary Table S3).

From the four fosmid clones the one derived from Lilliput (Lilli33G1) was the only one with significant $\mathrm{H}_{2}$ uptake activity at $25^{\circ} \mathrm{C}\left(66.4 \pm 13.0 \mathrm{nmol} \mathrm{H}_{2} / \mathrm{min} / \mathrm{mg}\right.$ partially purified protein) (Fig. 2a). All metagenomic fosmid clones exhibited an $\mathrm{H}_{2}$-uptake activity at $55^{\circ} \mathrm{C}(84.3 \pm 3.0$ to $257.6 \pm 18.5 \mathrm{nmol} \mathrm{H}_{2} / \mathrm{min} / \mathrm{mg}$ partially purified protein) (Fig. 2a). This may be related to the temperatures of the habitats the enzymes stem from, where Lilliput fluids have relatively low temperatures $\left(9^{\circ} \mathrm{C}\right)$, while Sisters Peak and Nibelungen emanate considerably hotter fluids (see Supplementary Table S3). Enzymes from warmer environments are usually optimized to function at elevated temperature as can be seen for proteins derived from hydrothermal vent inhabiting hyperthermophiles ([52] and references therein). No $\mathrm{H}_{2}$-uptake activity was obtained from the respective soluble fractions (data not shown). To our knowledge, the only three previously reported $\mathrm{H}_{2}$-uptake activities determined from recombinant $[\mathrm{NiFe}]$-hydrogenases displayed a relatively wide range of activities, i.e. $3.75 \mathrm{nmol} \mathrm{H}_{2} / \mathrm{min} / \mathrm{mg}$ of total protein, 150 and $444 \mathrm{nmol} \mathrm{H}_{2} / \mathrm{min} / \mathrm{mg}$ of partially purified proteins $[17,18,31]$. Thus, our metagenomic derived $\mathrm{H}_{2}$-uptake activities are in the upper range of the available activities found in the literature. In some cases our metagenome-derived activities even exceeded those measured for pure cultures [31, 53-56].

Hydrogen consumption was highest in the Nibelungen (Nib22E5) clone with $14.4 \pm 4.2 \%$ hydrogen consumption of a $80: 20 \mathrm{H}_{2}: \mathrm{CO}_{2}$ gas mixture after 3 weeks (Fig. 2b). The hydrogen that is consumed by clone Nib22E5 compares to the amount of hydrogen used by clone $\mathrm{P} 5 \mathrm{H} 2$ which is complemented with $S$. oneidensis' own hydrogenase gene cluster (Fig. 2b). Generally, not much microbial hydrogen consumption data are available from comparable experiments. The Epsilonproteobacterium Sulfurimonas
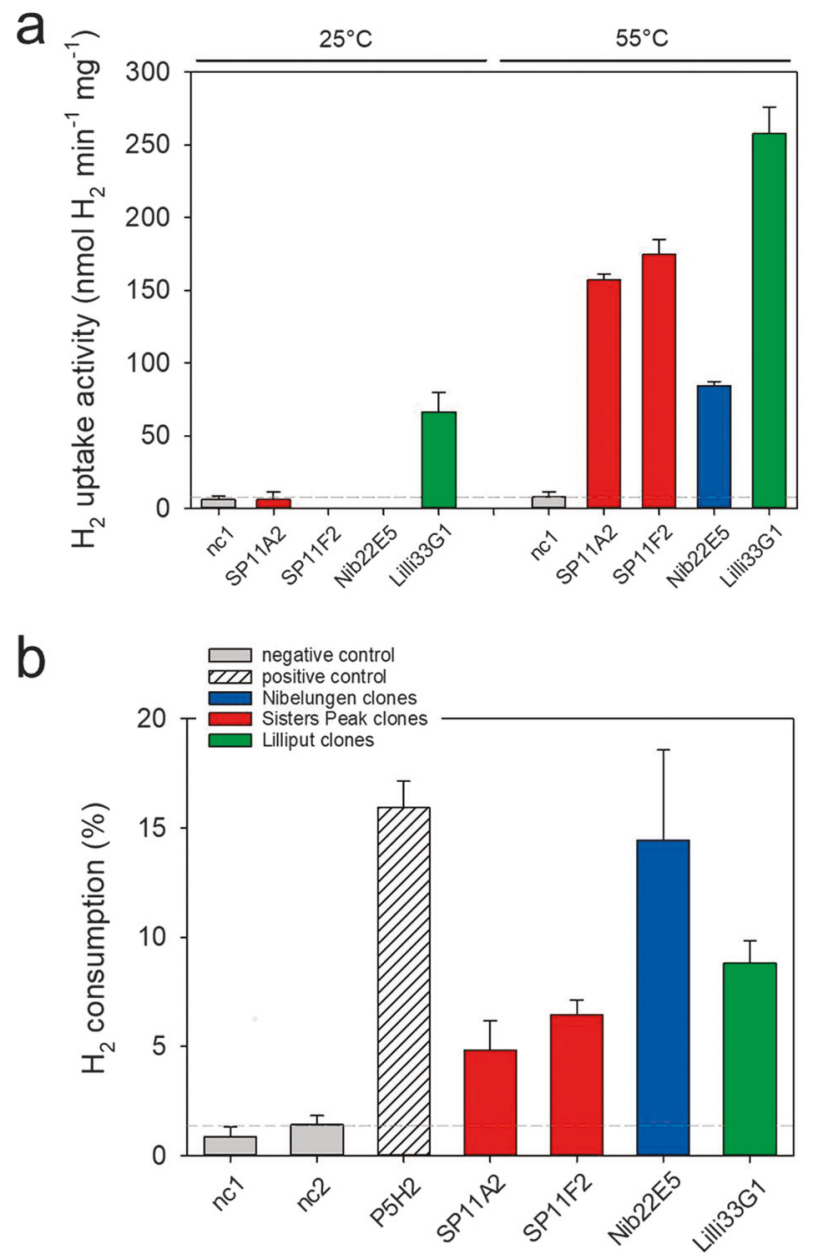

Fig. $2 \mathrm{H}_{2}$-uptake activities (a) and hydrogen consumption (b) of $S$. oneidensis $\triangle h y a B$ metagenomic fosmid clones. a Activities of membrane fractions from the clones of the three hydrothermal vent systems Sisters Peak, Nibelungen, and Lilliput are measured at 25 and at $55^{\circ} \mathrm{C}$. b Hydrogen consumption was measured at $28^{\circ} \mathrm{C}$. The negative controls are the deletion mutant $S$. oneidensis $\triangle h y a B$ (nc1) and $S$. oneidensis $\triangle$ hya $B$ harboring a $13 \mathrm{kbp}$ hydrogenase-free metagenomic RubisCO gene cluster (84G4II) (nc2). The positive control is P5H2 ( $S$. oneidensis $\triangle$ hyaB complemented with the hydrogenase gene cluster of $S$. oneidensis). The remaining four fosmid clones carried metagenomic DNA fragments from Sisters Peak (SP11A2 and SP11F2), Nibelungen (Nib22E5), and Lilliput (Lilli33G1). The sequence information of the metagenomic fosmid inserts is visualized in Fig. 3 and blastp results are detailed in Supplementary Table S4

denitrificans, for example, consumes 51 and $26 \%$ hydrogen of the $80: 20 \mathrm{H}_{2}: \mathrm{CO}_{2}$ gas mix within 14 days of incubation without or with added thiosulfate, respectively [31].

There are some discrepancies in the general trend found for the $\mathrm{H}_{2}$-uptake activities and hydrogen consumption measurements: $\mathrm{H}_{2}$-uptake activities related to the metagenomic fosmids are in most cases below detection limit at 25 ${ }^{\circ} \mathrm{C}$, but when expressed in $S$. oneidensis $\Delta$ hyaB, considerable amounts of the available hydrogen are consumed at comparable temperatures. Since our host S. oneidensis 
a) SP11A2

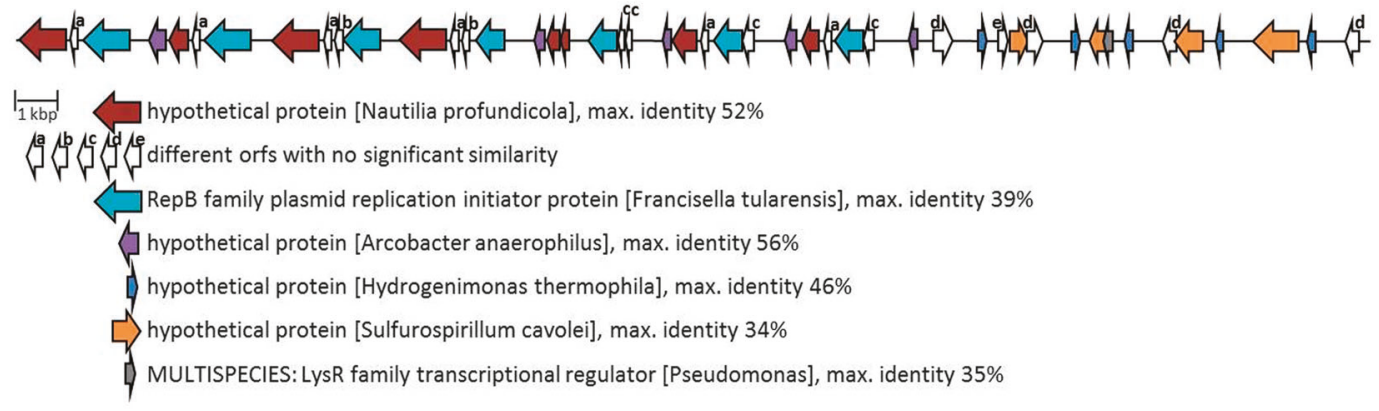

b) SP11F2

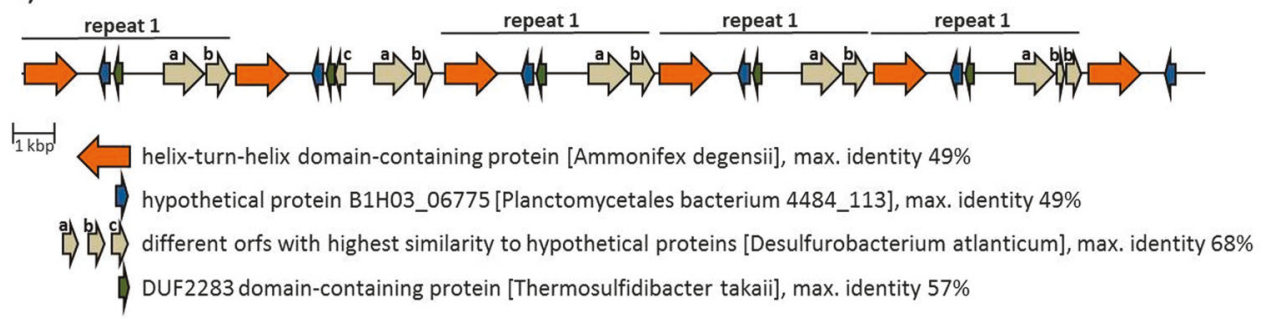

c) Nib22E5

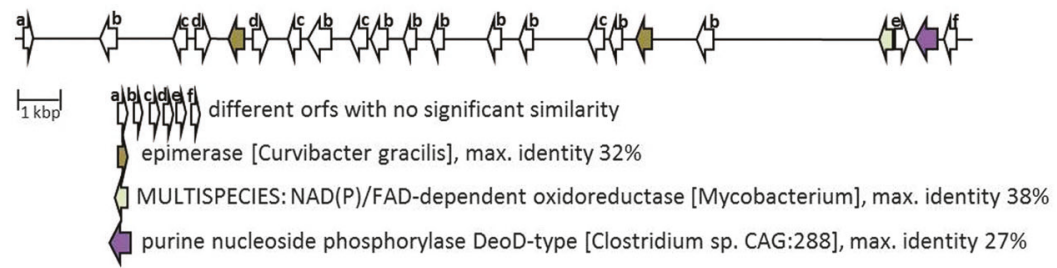

d) Lilli33G1

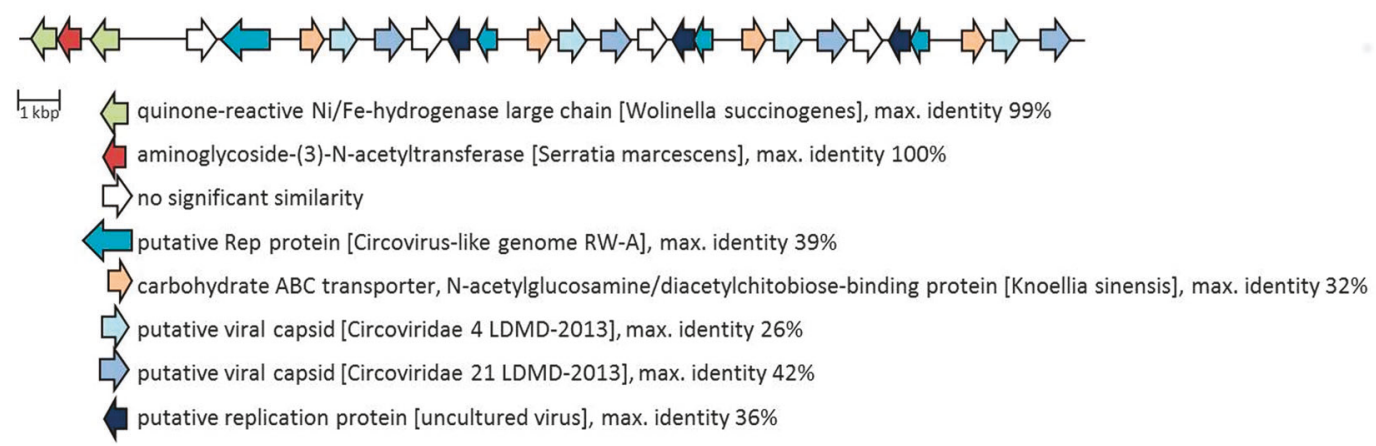

Fig. 3 Visualization of the putative ORFs on the metagenomic DNA fragments of the fosmid clones. Identified open reading frames of the metagenomic fosmid inserts of the four $\mathrm{H}_{2}$-uptake active clones are indicated as arrows in the direction of transcription. Arrows of the same color indicate the same amino acid sequence (lengths can vary) unless otherwise indicated by small letters. The corresponding blastp hits with the highest identity are shown below the gene arrangements. Details on the annotation of the open reading frames can be found in Supplementary Table S4 cannot grow at elevated temperatures, no hydrogen consumption measurements can be performed at $55^{\circ} \mathrm{C}$, thus lacking comparison for $\mathrm{H}_{2}$-uptake activities at $55^{\circ} \mathrm{C}$. A possible explanation for the thermal variability is that the $\mathrm{H}_{2}$ turnover rates of the respective enzymes at $25^{\circ} \mathrm{C}$ are so slow that they cannot be detected in the short time period of the $\mathrm{H}_{2}$-uptake activity measurements. The long incubation times until hydrogen consumption in the respective clones 
can be detected (up to 4 weeks compared to 2 to 3 days for the positive control) add to this theory.

One may argue that a spontaneous reversion of the mutant to its original hydrogen uptake phenotype falsely interpreted as activity derived from fosmid gene expression is the reason for the hydrogen conversion ability in the four metagenomic fosmid clones. However, this is not feasible for the following reasons: firstly, no hydrogen consumption or $\mathrm{H}_{2}$-uptake activity was measured for any of the negative controls, i.e. S. oneidensis $\Delta$ hyaB (nc1) and S. oneidensis $\triangle$ hyaB::pRS44_84G4II (nc2) - other than minor hydrogen-leakage from the serum bottles. Secondly, the mutant was constructed by deleting 1013 base pairs of the large subunit (including the motifs for the NiFe incorporation) of the structural gene of the [NiFe]-hydrogenase (total gene size 1703 base pairs) and replacing them with a gentamycin resistance cassette. In the activity-based screen all fosmid clones are grown on gentamycin. If the resistance gene is no longer present in the surrogate host (due to excision), growth is impossible. In the event that the gentamycin resistance gene jumped into another part of the host genome, the hydrogenase mutant would still not be able to use hydrogen as nearly two-third of the structural gene has been deleted and thus its functionality is significantly impaired.

\section{Sequencing the metagenomic DNA fragments}

PCR-based hydrogenase searches gave us only a single hit when screening the three libraries for [NiFe]-hydrogenase genes. The recovered sequence was identified in clone Lilli33G1 and resembled the large subunit of the quinone reactive $[\mathrm{NiFe}]-$ hydrogenase from Wolinella succinogenes (99\% AA identity) (for phylogeny see Supplementary Fig. S3). The activity-based screen identified four $\mathrm{H}_{2}-$ uptake active $S$. oneidensis $\triangle$ hyaB fosmid clones, namely SP11A2, SP11F2, Nib22E5, and Lilli33G1 (the latter was also detected by sequence-based approach). PacBio sequencing of these fosmids yielded four contigs. The metagenomic fragments were similar to orfs from Gamma-, Beta- and Epsilonproteobacteria, Firmicutes, Planctomycetes, Actinobacteria, Aquificae, and viruses. Only the Lilli33G1 fosmid insert encoded a gene similar to a hydrogenase in the database (99\% similarity to the [NiFe]hydrogenase from $W$. succinogenes). According to blastp the other orfs encoded on the metagenomic fragments had generally very low identities to other known sequences: SP11A2 - no significant hit or 34-56\% AA similarity, SP11F2 49-68\% AA similarity, Nib22E5 no significant hit or $27-38 \%$ AA similarity, and Lilli33G1 26-99\% AA similarity (see Fig. 3 and Supplementary Table S4). Hidden Markov-model searches with thresholds set to bit scores of 1.0 for single domains could not identify any classical hydrogenase motifs ([NiFe]-, [FeFe]-, and [Fe]-hydrogenases were considered) in the orfs of the three metagenomic inserts from clones SP11A2, SP11F2, or Nib22E5. This, however, is not unusual. Activity-based screens applied to metagenomic fosmid, phagemid, or plasmid clones have repeatedly retrieved enzymes with sought for specific activities. Nevertheless, often the respective metagenomic inserts encode proteins which show no similarity to any other known gene or subsequent sequence-based searches fail to find significant similarities to known proteins of the expected gene product class [57-60]. As a consequence, several new enzyme classes for these recombinant enzymes recovered through such activitybased assays have been suggested [59, 61].

When sequencing the metagenomic fosmid inserts we encountered several repeats. Today's sequencing technology cannot resolve such repeats if they occur in the natural environment and possibly also not when sequencing genomes, unless using sequence technologies that produce very long reads. Therefore, we cannot exclude that these repeats are real. However, we believe that the high number of repeats in the metagenomic fragments is related to MDA, which we had to apply to generate sufficient amounts of DNA for fosmid library construction. MDA is known to cause bias when amplifying metagenomic DNA [62], but the bias is much smaller than that of other (PCR-based) whole-genome amplification methods [63, 64], making it the preferential method for the amplification of low biomass environmental DNA. Nevertheless, even though the DNA fragments may be manipulated through MDA, the screen itself combined with metagenome amplified DNA still has the potential to identify genes and respective enzymes with hydrogen uptake ability. This approach may actually be beneficial if searching for recombinant enzymes with high $\mathrm{H}_{2}$-uptake ability, where the activity of the fragment matters more (repeats of genes encoding hydrogen uptake enzymes increase activity) than whether the sequence of genes is altered compared to what is found in the environment. In ecological studies, however, it will be vital to provide sufficient amounts of clean, unaltered DNA for metagenomic fosmid library construction and respective screening.

\section{Conclusion}

The knowledge of hydrogen-converting organisms and their enzymes is limited by our ability to culture the microorganisms. The comparison of metagenomic and transcriptomic sequences is restricted by the genes and respective products that have been characterized and that are thus available in the databases for comparison. Although activity-based screens also have some drawbacks, related to problems of expressing metagenomic DNA in a surrogate 
host, our screen can help fill the gap to identify and study hydrogenases from uncultured organisms that would not have been found otherwise by available sequence- or culture-based techniques. Needless to say that not all bacterial and archaeal hydrogenases can be identified with the host-vector system used here, indicating how imperative it is to further develop this screen by using alternative hosts for expressing the enzymes. Nevertheless, the good recovery (rate) of $\mathrm{H}_{2}$-uptake enzymes, the relatively high levels of enzymatic $\mathrm{H}_{2}$-uptake activity, and in vivo hydrogen consumption of hydrogenase mutants containing fosmids with metagenomic inserts as well as the limited similarity to known hydrogenases indicate the large hydrogenconverting potential that can be found among the unculturables in deep-sea hydrothermal vent environments and likely beyond. Although this screen is very laborious and it takes roughly 4.5 weeks to screen $8-12$ pools consisting each of 48 fosmid clones (and another 3 months to break $\mathrm{H}_{2}$-uptake active pools down to one individual positive clone), it is, to our knowledge, currently the only way to identify and recover novel enzymes capable of hydrogen conversion from uncultured organisms.

Three of our four metagenomic inserts of the fosmid clones conferring $\mathrm{H}_{2}$-uptake activity and hydrogen consumption ability lacked sequence homology to known hydrogenases. In fact, searches for several of the orfs failed to find significant similarities to any of the known protein families opting for a new type of hydrogen-converting enzyme. [Fe]-hydrogenases are an example of an uncommon hydrogenase-if [ $\mathrm{NiFe}]-$ and [ $\mathrm{FeFe}]-$ hydrogenases are considered a typical hydrogenase-since they lack iron-sulfur clusters and do not contain redox-active transition metalsalthough iron is required for enzyme activity [65]. In hydrothermal vents (rare) metals can be readily available and evolution may have produced an enzyme in such a system that is different to the common and known types of hydrogenases. Also, with a different redox-active center than that found in the classic hydrogenases, where the organometallic ligands are coordinated to the iron center, assembly of the structural protein may be considerably less complex and require less (if any) assembly and maturation proteins. Conclusively, given the relatively high $\mathrm{H}_{2}$-uptake activities, the hydrogen consumption and the lack of (significant) homologies to known sequences, we postulate that alternative mechanisms for hydrogen conversion exist. Future work should address the identification of the orfs from the metagenomic fragments encoding hydrogen conversion (subcloning, transposon mutagenesis) and description of the protein structure (crystallization) to expand our understanding of hydrogen conversion in nature.

Acknowledgements We thank the Captain and crews of the R/V Meteor and ROV Kiel6000 for helping us to obtain hydrothermal vent samples. Furthermore, we are indebted to Dr. Kai Thormann for providing the suicide vector pNPTS138R6KT to construct the mutant and the Shewanella oneidensis MR-1 strain as well as Dr. Harald Huber for providing the A. aeolicus DNA. We also greatly appreciate that Prof. Svein Valla supplied the pRS44 broad host range fosmid vector and the appendant pTA66 plasmid. We thank Nicolas Rychlik for constructing the $S$. oneidensis $\Delta$ hyaB mutant and for support with developing the screen as well as numerous technical assistant-students for picking clones. We also thank Dominik Danso for help with performing the hidden Markov-Model searches.

Funding This work was supported by the research grant DFG PE1549-6/1 from the German Science Foundation.

\section{Compliance with ethical standards}

Conflict of interest The authors declare that they have no conflict of interest.

\section{References}

1. Schlapbach L, Zuttel A. Hydrogen-storage materials for mobile applications. Nature. 2001;414:353-8.

2. Bothe H, Schmitz O, Yates MG, Newton WE. Nitrogen fixation and hydrogen metabolism in cyanobacteria. Microbiol Mol Biol Rev. 2010;74:529-51.

3. Dilling W, Cypionka H. Aerobic respiration in sulfate-reducing bacteria. FEMS Microbiol Lett. 1990;71:123-7.

4. Hallenbeck PC. Fermentative hydrogen production: principles, progress, and prognosis. Int J Hydrog Energy. 2009;34:7379-89.

5. Vignais PM, Billoud B. Occurrence, classification, and biological function of hydrogenases: an overview. Chem Rev. 2007;107:4206-72.

6. Thauer RK, Biochemistry of methanogenesis: a tribute to Marjory Stephenson. Microbiology. 1998;144(Pt 9):2377-406.

7. Brugna-Guiral M, Tron P, Nitschke W, Stetter KO, Burlat B, Guigliarelli B, et al. [NiFe] hydrogenases from the hyperthermophilic bacterium Aquifex aeolicus: properties, function, and phylogenetics. Extremophiles. 2003;7:145-57.

8. Vargas WA, Weyman PD, Tong YK, Smith HO, Xu Q. [NiFe] hydrogenase from Alteromonas macleodii with unusual stability in the presence of oxygen and high temperature. Appl Environ Microbiol. 2011;77:1990-8.

9. Amann RI, Ludwig W, Schleifer KH. Phylogenetic identification and in situ detection of individual microbial cells without cultivation. Microbiol Rev. 1995;59:143-69.

10. Greening C, Biswas A, Carere CR, Jackson CJ, Taylor MC, Stott $\mathrm{MB}$, et al. Genomic and metagenomic surveys of hydrogenase distribution indicate $\mathrm{H}_{2}$ is a widely utilised energy source for microbial growth and survival. ISME J. 2016;10:761-77.

11. Nakagawa $S$, Takai K, Inagaki F, Hirayama $H$, Nunoura $T$, Horikoshi K, et al. Distribution, phylogenetic diversity and physiological characteristics of Epsilonproteobacteria in a deep-sea hydrothermal field. Environ Microbiol. 2005;7:1619-32.

12. Perner M, Petersen JM, Zielinski F, Gennerich HH, Seifert R. Geochemical constraints on the diversity and activity of $\mathrm{H}_{2}$-oxidizing microorganisms in diffuse hydrothermal fluids from a basalt- and an ultramafic-hosted vent. FEMS Microbiol Ecol. 2010;74:55-71.

13. Handelsman J. Metagenomics: application of genomics to uncultured microorganisms. Microbiol Mol Biol Rev. 2004;68:669-85.

14. Bock A, King PW, Blokesch M, Posewitz MC. Maturation of hydrogenases. Adv Microb Physiol. 2006;51:1-71. 
15. Casalot L, Rousset M. Maturation of the [NiFe] hydrogenases. Trends Microbiol. 2001;9:228-37.

16. Blokesch M, Magalon A, Bock A. Interplay between the specific chaperone-like proteins $\mathrm{HybG}$ and HypC in maturation of hydrogenases 1, 2, and 3 from Escherichia coli. J Bacteriol. 2001;183:2817-22.

17. Rousset M, Magro V, Forget N, Guigliarelli J, Hatchikian EC. Heterologous expression of the Desulfovibrio gigas [NiFe] hydrogenase in Desulfovibrio fructososvorans MR400. J Bacteriol. 1998;180:4982-6.

18. Maroti G, Tong Y, Yooseph S, Baden-Tillson H, Smith HO, Kovacs $\mathrm{KL}$, et al. Discovery of $[\mathrm{NiFe}]$ hydrogenase genes in metagenomic DNA: cloning and heterologous expression in Thiocapsa roseopersicina. Appl Environ Microbiol. 2009;75:5821-30.

19. Kelley DS, Baross JA, Delaney JR. Volcanoes, fluids, and life at mid-ocean ridge spreading centers. Annu Rev Earth Planet Sci. 2002;30:385-491.

20. McCollom TM, Shock EL. Geochemical constraints on chemolithoautotrophic metabolism by microorganisms in seafloor hydrothermal systems. Geochim Cosmochim Acta. 1997;61:4375-91.

21. Perner M, Hansen M, Seifert R, Strauss H, Koschinsky A, Petersen S. Linking geology, fluid chemistry, and microbial activity of basalt- and ultramafic-hosted deep-sea hydrothermal vent environments. Geobiology. 2013;11:340-55.

22. Petersen JM, Zielinski FU, Pape T, Seifert R, Moraru C, Amann $\mathrm{R}$, et al. Hydrogen is an energy source for hydrothermal vent symbioses. Nature. 2011;476:176-80.

23. Perner M, Gonnella G, Kurtz S, LaRoche J. Handling temperature bursts reaching $464^{\circ} \mathrm{C}$ : different microbial strategies in the Sisters Peak hydrothermal chimney. Appl Environ Microbiol. 2014;80:4585-98.

24. Adam N, Perner M. Activity-based screening of metagenomic libraries for hydrogenase enzymes. In: Streit WR, Daniel R, editors. Metagenomics: methods and protocols. New York, NY: Springer New York; 2017. p. 261-70.

25. Liu C, Gorby YA, Zachara JM, Fredrickson JK, Brown CF. Reduction kinetics of $\mathrm{Fe}(\mathrm{III}), \mathrm{Co}(\mathrm{III}), \mathrm{U}(\mathrm{VI}), \mathrm{Cr}(\mathrm{VI})$, and $\mathrm{Tc}(\mathrm{VII})$ in cultures of dissimilatory metal-reducing bacteria. Biotechnol Bioeng. 2002;80:637-49.

26. Lovley DR, Phillips EJ, Lonergan DJ. Hydrogen and formate oxidation coupled to dissimilatory reduction of iron or manganese by Alteromonas putrefaciens. Appl Environ Microbiol. 1989;55:700-6.

27. Balch WE, Fox GE, Magrum LJ, Woese CR, Wolfe RS. Methanogens: reevaluation of a unique biological group. Microbiol Rev. 1979;43:260-96.

28. Sako Y, Takai K, Ishida Y, Uchida A, Katayama Y. Rhodothermus obamensis sp. nov., a modern lineage of extremely thermophilic marine bacteria. Int J Syst Bacteriol. 1996;46:1099-104.

29. Weaver PF, Wall JD, Gest H. Characterization of Rhodopseudomonas capsulata. Arch Microbiol. 1975;105:207-16.

30. Krafft T, Gross R, Kroger A. The function of Wolinella succinogenes $p s r$ genes in electron transport with polysulphide as the terminal electron acceptor. Eur J Biochem. 1995;230:601-6.

31. Han Y, Perner M. The role of hydrogen for Sulfurimonas denitrificans' metabolism. PLOS ONE. 2014;9:e106218.

32. Böhnke S, Perner M. A function-based screen for seeking RubisCO active clones from metagenomes: novel enzymes influencing RubisCO activity. ISME J. 2015;9:735-45.

33. Bergmans HE, van Die IM, Hoekstra WP. Transformation in Escherichia coli: stages in the process. J Bacteriol. 1981;146:564-70.

34. Garbe-Schönberg D, Koschinsky A, Ratmeyer V, Jähmlich H, Westernströer U. KIPS-a new multiport malve-based all-teflon fluid sampling system for ROVs. EGU Meeting, Vienna, Austria. Geophysical Research Abstracts, 2006.

35. Perner M, Hentscher M, Rychlik N, Seifert R, Strauss H, Bach W. Driving forces behind the biotope structures in two lowtemperature hydrothermal venting sites on the southern MidAtlantic Ridge. Environ Microbiol Rep. 2011;3:727-37.

36. Perner M, Seifert R, Weber S, Koschinsky A, Schmidt K, Strauss $\mathrm{H}$, et al. Microbial $\mathrm{CO}_{2}$ fixation and sulfur cycling associated with low-temperature emissions at the Lilliput hydrothermal field, southern Mid-Atlantic Ridge $\left(9^{\circ} \mathrm{S}\right)$. Environ Microbiol. 2007;9:1186-201.

37. Perner M, Bach W, Hentscher M, Koschinsky A, GarbeSchonberg D, Streit WR, et al. Short-term microbial and physico-chemical variability in low-temperature hydrothermal fluids near 5 degrees $\mathrm{S}$ on the Mid-Atlantic Ridge. Environ Microbiol. 2009;11:2526-41.

38. Aakvik T, Degnes KF, Dahlsrud R, Schmidt F, Dam R, Yu L, et al. A plasmid RK2-based broad-host-range cloning vector useful for transfer of metagenomic libraries to a variety of bacterial species. Fems Microbiol Lett. 2009;296:149-58.

39. Altschul SF, Madden TL, Schaffer AA, Zhang J, Zhang Z, Miller $\mathrm{W}$, et al. Gapped BLAST and PSI-BLAST: a new generation of protein database search programs. Nucleic Acids Res. 1997;25:3389-402.

40. Takai K, Campbell BJ, Cary SC, Suzuki M, Oida H, Nunoura T, et al. Enzymatic and genetic characterization of carbon and energy metabolisms by deep-sea hydrothermal chemolithoautotrophic isolates of Epsilonproteobacteria. Appl Environ Microb. 2005;71:7310-20.

41. Lassak J, Henche AL, Binnenkade L, Thormann KM. ArcS, the cognate sensor kinase in an atypical Arc system of Shewanella oneidensis MR-1. Appl Environ Microbiol. 2010;76:3263-74.

42. Green MR, Sambrook J. Molecular cloning: a labarotory manual. 4th ed. Cold Spring Harbor, New York: CSHL Press; 2012.

43. Bradford MM. A rapid and sensitive method for the quantitation of microgram quantities of protein utilizing the principle of protein-dye binding. Anal Biochem. 1976;72:248-54.

44. Guiral M, Tron P, Belle V, Aubert C, Leger C, Guigliarelli B, et al. Hyperthermostable and oxygen resistant hydrogenases from a hyperthermophilic bacterium Aquifex aeolicus: physicochemical properties. Int J Hydrog Energy. 2006;31:1424-31.

45. Hansen M, Perner M. A novel hydrogen oxidizer amidst the sulfuroxidizing Thiomicrospira lineage. ISME J. 2015;9:696-707.

46. Hyatt D, Chen GL, Locascio PF, Land ML, Larimer FW, Hauser LJ. Prodigal: prokaryotic gene recognition and translation initiation site identification. BMC Bioinformatics. 2010;11:119.

47. Notredame C, Higgins DG, Heringa J. T-Coffee: a novel method for fast and accurate multiple sequence alignment. J Mol Biol. 2000;302:205-17.

48. Mistry J, Finn RD, Eddy SR, Bateman A, Punta M. Challenges in homology search: HMMER3 and convergent evolution of coiledcoil regions. Nucleic Acids Res. 2013;41:e121.

49. Uchiyama T, Miyazaki K. Functional metagenomics for enzyme discovery: challenges to efficient screening. Curr Opin Biotechnol. 2009;20:616-22.

50. Culligan EP, Sleator RD, Marchesi JR, Hill C. Metagenomics and novel gene discovery: promise and potential for novel therapeutics. Virulence. 2014;5:399-412.

51. Penesyan A, Ballestriero F, Daim M, Kjelleberg S, Thomas T, Egan S. Assessing the effectiveness of functional genetic screens for the identification of bioactive metabolites. Mar Drugs. 2012;11:40-49.

52. Zierenberg RA, Adams MW, Arp AJ. Life in extreme environments: hydrothermal vents. Proc Natl Acad Sci USA. 2000;97:12961-2. 
53. Elsen S, Colbeau A, Chabert J, Vignais PM. The hupTUV operon is involved in negative control of hydrogenase synthesis in Rhodobacter capsulatus. J Bacteriol. 1996;178:5174-81.

54. Hansen M, Perner M. Hydrogenase gene distribution and $\mathrm{H}_{2}$ consumption ability within the Thiomicrospira lineage. Front Microbiol. 2016;7:99. https://doi.org/10.3389/fmicb.2016.00099.

55. Nishihara H, Miyashita Y, Aoyama K, Kodama T, Igarashi Y, Takamura Y. Characterization of an extremely thermophilic and oxygen-stable membrane-bound hydrogenase from a marine hydrogen-oxidizing bacterium Hydrogenovibrio marinus. Biochem Bioph Res Commun. 1997;232:766-70.

56. Shi L, Belchik SM, Plymale AE, Heald S, Dohnalkova AC, Sybirna K, et al. Purification and characterization of the [NiFe]hydrogenase of Shewanella oneidensis MR-1. Appl Environ Microbiol. 2011;77:5584-90.

57. Knietsch A, Waschkowitz T, Bowien S, Henne A, Daniel R. Construction and screening of metagenomic libraries derived from enrichment cultures: generation of a gene bank for genes conferring alcohol oxidoreductase activity on Escherichia coli. Appl Environ Microbiol. 2003;69:1408-16.

58. Knietsch A, Waschkowitz T, Bowien S, Henne A, Daniel R. Metagenomes of complex microbial consortia derived from different soils as sources for novel genes conferring formation of carbonyls from short-chain polyols on Escherichia coli. J Mol Microbiol Biotechnol. 2003;5:46-56.
59. Beloqui A, Pita M, Polaina J, Martinez-Arias A, Golyshina OV, Zumarraga $\mathrm{M}$, et al. Novel polyphenol oxidase mined from a metagenome expression library of bovine rumen: biochemical properties, structural analysis, and phylogenetic relationships. J Biol Chem. 2006;281:22933-42.

60. Beloqui A, Nechitaylo TY, Lopez-Cortes N, Ghazi A, Guazzaroni ME, Polaina J, et al. Diversity of glycosyl hydrolases from cellulose-depleting communities enriched from casts of two earthworm species. Appl Environ Microbiol. 2010;76:5934-46.

61. Ferrer M, Beloqui A, Timmis KN, Golyshin PN. Metagenomics for mining new genetic resources of microbial communities. J Mol Microbiol Biotechnol. 2009;16:109-23.

62. Lasken RS, Stockwell TB. Mechanism of chimera formation during the multiple displacement amplification reaction. BMC Biotechnol. 2007;7:19.

63. Dean FB, Hosono S, Fang L, Wu X, Faruqi AF, Bray-Ward P, et al. Comprehensive human genome amplification using multiple displacement amplification. Proc Natl Acad Sci USA. 2002;99:5261-6.

64. Hosono S, Faruqi AF, Dean FB, Du Y, Sun Z, Wu X, et al. Unbiased whole-genome amplification directly from clinical samples. Genome Res. 2003;13:954-64.

65. Lyon EJ, Shima S, Buurman G, Chowdhuri S, Batschauer A, Steinbach K, et al. UV-A/blue-light inactivation of the 'metal-free' hydrogenase (Hmd) from methanogenic archaea. Eur J Biochem. 2004;271:195-204. 